\title{
Smarter Together: Progressing Smart Data Platforms in Lyon, Munich, and Vienna
}

\author{
Naomi Morishita-Steffen ${ }^{1, *(D)}$, Rémi Alberola ${ }^{2}$, Baptiste Mougeot ${ }^{2}$ D , Étienne Vignali ${ }^{2}$, Camilla Wikström $^{3}{ }^{(D)}$, \\ Uwe Montag ${ }^{4}$, Emmanuel Gastaud ${ }^{5}$, Brigitte Lutz ${ }^{6}{ }^{D}$, Gerhard Hartmann ${ }^{7}$, Franz Xaver Pfaffenbichler ${ }^{7}$, \\ Ali Hainoun ${ }^{8}\left(\mathbb{D}\right.$, Bruno Gaiddon ${ }^{9}$, Antonino Marvuglia ${ }^{10}$ and Maria Beatrice Andreucci ${ }^{11}$ (D)
}

1 E207-02-Research Unit of Building Physics, Institute of Material Technology, Building Physics, and Building Ecology, Faculty of Civil Engineering, Vienna University of Technology, Karlsplatz 13, 1040 Vienna, Austria

2 SPL Lyon Confluence, 73, Rue Smith, 69002 Lyon, France; remi.alberola@hotmail.fr (R.A.); bmougeot@lyon-confluence.fr (B.M.); evignali@lyon-confluence.fr (É.V.)

3 Transport Department, City of Stockholm, Tekniska Nämndhuset, Fleminggatan 4, 11226 Stockholm, Sweden; camilla.wikstrom@stockholm.se

4 Section I-IT Strategy and IT Governance/IT Controlling (STRAC), Department for Information and Telecommunications Technology, A2-E/O-Gov and Smart City, City of Munich, 80992 Munich, Germany; uwe.montag@muenchen.de

5 Métropole de Lyon, 20, rue du Lac CS 33569, CEDEX 3, 69505 Lyon, France; egastaud@grandlyon.com

6 Chief Executive Office, Executive Group for Organisation, Safety and Security, Process Management and ICT-Strategy, City of Vienna, Rathausstraße 8, 1010 Vienna, Austria; brigitte.lutz@wien.gv.at

7 Vienna Digital, City of Vienna, Stadlauer Straße 54 and 56, 1220 Vienna, Austria; gerhard.hartmann@wien.gv.at (G.H.); xaver.pfaffenbichler@wien.gv.at (F.X.P.)

check for updates

Citation: Morishita-Steffen, N.; Alberola, R.; Mougeot, B.; Vignali, É.; Wikström, C.; Montag, U.; Gastaud, E.; Lutz, B.; Hartmann, G.; Pfaffenbichler, F.X.; et al. Smarter Together: Progressing Smart Data Platforms in Lyon, Munich, and Vienna. Energies 2021, 14, 1075. https://doi.org/10.3390/en14041075

Academic Editors: Barry Hayes and Vahid Hosseinnezhad

Received: 12 January 2021

Accepted: 10 February 2021

Published: 18 February 2021

Publisher's Note: MDPI stays neutral with regard to jurisdictional claims in published maps and institutional affiliations.

Copyright: (c) 2021 by the authors. Licensee MDPI, Basel, Switzerland. This article is an open access article distributed under the terms and conditions of the Creative Commons Attribution (CC BY) license (https:/ / creativecommons.org/licenses/by/ $4.0 /)$.
8 Center for Energy, Digital Resilient Cities, AIT Austrian Institute of Technology GmbH, Giefinggasse 4, 1210 Vienna, Austria; Ali.Hainoun@ait.ac.at

9 Photovoltaic Department, Hespul, 14 Place Jules Ferry, 69006 Lyon, France; bruno.gaiddon@hespul.org

10 Environmental Sustainability Assessment and Circularity Unit, Environmental Research \& Innovation Department, Luxembourg Institute of Science and Technology (LIST), 5, Avenue des Hauts-Fourneaux, L-4362 Esch-sur-Alzette, Luxembourg; antonino.marvuglia@list.lu

11 Department of Planning, Design, Technology of Architecture, "Sapienza" University of Rome, Via Flaminia 72, 00196 Rome, Italy; mbeatrice.andreucci@uniroma1.it

* Correspondence: naomi.morishita@tuwien.ac.at; Tel.: +49-173-532-5187 policies, smart data platforms are a tool for collecting a great deal of information on the territory and a means of producing effective public policies to meet contemporary challenges, improve the quality of the city, and create new services. Within the framework of the Smarter Together project, the cities of Lyon (France), Munich (Germany), and Vienna (Austria) have integrated this tool into their city's metabolism and use it at different scales. Nevertheless, the principle remains the same: the collection (or even dissemination) of internal and external data to the administration will enable the communities, companies, not-for-profit organizations, and civic administrations to "measure" the city and identify areas for improvement in the territory. Furthermore, through open data logics, public authorities can encourage external partners to become actors in territorial action by using findings from the data to produce services that will contribute to the development of the territory and increase the quality of the city and its infrastructure. Nevertheless, based on data that is relatively complex to extract and process, public data platforms raise many legal, technical, economic, and social issues. The cities either avoided collecting personal data or when dealing with sensitive data, use anonymized aggregated data. Cocreation activities with municipal, commercial, civil society stakeholders, and citizens adopted the strategies and tools of the intelligent data platforms to develop new urban mobility and government informational services for both citizens and public authorities. The data platforms are evolving for transparent alignment with 2030 climate-neutrality objectives while municipalities strive for greater agility to respond to disruptive events like the COVID-19 pandemic.

Keywords: smart city initiatives; big data; lighthouse cities; data management system; urban modeling 


\section{Introduction}

Today, technological innovation seems fast and elusive [1]. At the heart of society, the debate crystallizes around two positions: those who consider digital technology as a major vector of progress, and those who believe it is a risk for society. Nevertheless, the postulate remains the same: the digital domain has permeated our lives [1]. Experts in the field perceive the gradual penetration of digital technologies into society is akin to a fourth industrial revolution $[2,3]$.

Implying profound societal changes, a new relationship to work, a new connection to cities, and a possibility to provide "adaptive" contemporary solutions, digital technology is becoming a new driving force in the organization of society as a whole [3].

It is in this context that the "Smart City" began to emerge during the first decade of the 21st Century [1,4-6]. At that time, major IT firms such as Cisco and IBM promoted the concept by developing digital platforms dedicated to city management for local authorities [7]. The digitization was meant to be a means to attain greater efficiency [8]. Since then, the term Smart City is in wide use, and a diverse array of new subjects has emerged [7,9]. Nevertheless, the presence of digital tools in the intelligent city remains preponderant [10].

Many cities around the world have implemented a combination of both high- and low-tech smart city digital solutions. All digital services should be integrated into the new platforms to unfold the full value potential for each service and the digital platforms.

Data collection, management, and processing are becoming increasingly important for cities as a new way of responding to the dynamic challenges that cities face today and will face in the future. One of the cornerstones of smart city development is data management linked to smart services. It is necessary to develop high and low-tech municipal solutions simultaneously [11]. Many cities worldwide have already implemented integrated digital solutions using both approaches, unfolding the full value potential for new platforms and services [11].

Perceived as a real tool to meet the challenges in today's world such as demographic growth, climate mitigation, and resource management, public authorities are now using digital tools to implement public policies to create more sustainable, safe, and efficient cities [12]. Ever faced with new challenges, cities are increasingly using digital data platforms to obtain local information on the territory for responding to unforeseen new situations such as the COVID-19 pandemic and climate change $[10,13,14]$. Riding the digital wave, and taking advantage of the development of new technologies, the EU encourages these innovative initiatives at the local level by financing projects within the Horizon 2020 Smart Cities and Communities Research Framework [15].

\section{Smarter Together and the Role of Digital Technology}

Smarter Together (ST) brings together stakeholders from the local government, industry, research, and individual citizens for developing, demonstrating, and replicating smart city innovations. Each lighthouse city (LHC) is an urban renewal district under redevelopment as a Smart City innovation laboratory demonstrating solutions in five key domains: data management platform and smart services, district heating and renewables, e-mobility, holistic refurbishment, and citizen and stakeholder engagement. The "data management platform \& smart services" domain is central to the project, connecting with all other areas: district heating and renewables, e-mobility, and holistic refurbishment. Citizen and stakeholder engagement surround all project activities representing the importance of involving stakeholders and individual citizens in the innovation process [11].

Using the examples of Lyon, Munich, and Vienna as lighthouse cities (LHCs) of the Horizon 2020 Smarter Together project, this article shows how each smart city implemented a smart data platform to develop new services for collecting data to make building energy performance indicators visible and to offer new/improved data-based municipal services raising life quality for citizens [15]. By highlighting the case studies in the three cities, other "smart" cities can use these models for implementing their municipal data platforms. The implementation of this innovative tool raises many questions in legal, technical, economic, 
and social contexts, and is thus a real challenge for public authorities. In the next sections, the urban context and the digital strategy of each city where the digital platform is implemented are described. In the following parts, the data collection and the actual results produced by the data about the cities are presented. Finally, the future of digital platforms is discussed.

\section{Methodology}

The overall objectives of digital management platforms (DMPs) in ST are to increase the number of available data sets for facilitating shared monitoring results and automated data transfer between project partners. Another goal is to stimulate an understanding of how related infrastructures can be linked while including a diverse array of urban stakeholders.

The DMP platforms in each city aim to create a common virtual ecosystem for sharing open and non-open data between authorized parties, and for developing new services and applications accommodating the growing number of collected data sets serving policy, governance, and citizen participation requirements when implementing and utilizing the new digital services.

An objective of Smart Data Platforms (SDPs) is to use the available data to find smart solutions, e.g., accessing shared mobility stations, tracking household energy consumption, or tracking local renewable energy production, supporting citizens in their daily lives. Cities intend to increase the availability of meaningful datasets. Local authorities strive to establish data platforms for monitoring and automated data transfer between project partners and to stimulate an understanding of how the related infrastructure can include participation by various municipal stakeholders.

Lyon, Munich, and Vienna, as lighthouse cities (LHCs) of the Smarter Together (ST) project, illustrate different SDP implementations for new data-based services visualizing building energy performance indicators and to offer new data-based municipal services improving urban quality of life. If invisible data is at the heart of this process, it is significant to remember that digital solutions rely above all on physical infrastructures.

This paper is based upon a combination of the authors' experiences within the project, personal interviews with other ST team members in each city who are or were involved in the conception, implementation, and follow-up processes, and internal and publicly available project deliverables [11,16-19].

\subsection{Development Phases}

The following description of the development process is based on Deliverable 2.1.3 [19]. The process began by establishing a knowledge exchange network with stakeholders from all eight cities in the ST network, including representatives from municipalities, research, industrial partners, and local citizens' groups. Goals were set within a collective iterative learning process to link all thematic fields and to create an open and active knowledge exchange environment transgressing hierarchical structures.

A four-step approach was taken to meet the targets:

1. Common reporting;

2. Project books;

3. Knowledge carriers;

4. P2P workshops.

Three biannual questionnaires, in August 2017, February 2018, and August 2018 formed the basis for common reporting. The output from common reporting formed the basis for the "Data Management Platform \& Smart Services" project books, knowledge carriers, and P2P workshops.

A project book per thematic topic and city summarizes the projects and solutions available to all project partners. Each project book was updated with supplemental information from each subsequent common reporting exercise. 
The knowledge carriers are the prototypes for each urban SDP, based on the content from the common reporting frameworks and the project books. Each knowledge carrier provided a three-dimensional visualization of project-specific information ascertained as important for each LHC at three levels: city, theme, and solution.

Shared challenges, exchange of best practices, and lessons learned for cocreation of solutions were achieved in a series of three P2P workshops involving the knowledge exchange network. External experts were invited bringing examples from best practices and lessons learned from other LHCs and implemented projects.

\subsection{The Evolution of the Grand Lyon Data Platform}

The Grand Lyon Data Platform has been in operation since 2013, offering 99\% publicly accessible data. Authentication mechanisms protect access to sensitive semi-private and private data on the platform based on Open-Source software standards. The smart dataplatform successfully stores private data securely.

The Confluence monitoring system (CMS) is the first digital dashboard developed by the Grand Lyon (the Greater Lyon Region, a.k.a. Métropole de Lyon) to collect and visualize energy data. The CMS addresses four use-cases defined by the Lyon La Confluence Team for the ST project. The use cases ensure compliance with design objectives and specifications, evaluate building performance for efficient building systems operation, provide individual residential energy consumption profiles for individual households of refurbished buildings, monitor overall energy production from renewable sources, and monitor total energy consumption in the Lighthouse Quarter. Data with 10-min, 30-min, or hourly time steps are uploaded daily to the data platform. CMS development and connection to the Data Platform is one of the replication projects in ST [17].

SPL Lyon Confluence (SPL) created the first data platform for La Confluence in parallel to a larger metropolitan platform initiated by Grand Lyon for the Greater Lyon Area. Since 2010, data platforms in several major French cities within the Greater Lyon Region (France) analyze municipal data sets to offer new citizen services. Local authorities partnered with external companies to develop new public services using open data. The data from La Confluence provides inputs for the Grand Lyon SDP, Figure 1. Today, the building energy data of the building stock, including both new construction and the thermally refurbished buildings, is automatically uploaded to the data platform. Data from both building energy consumption and on-site electricity generation are included, enabling the energy performance of the La Confluence building stock to be monitored and evaluated over time.

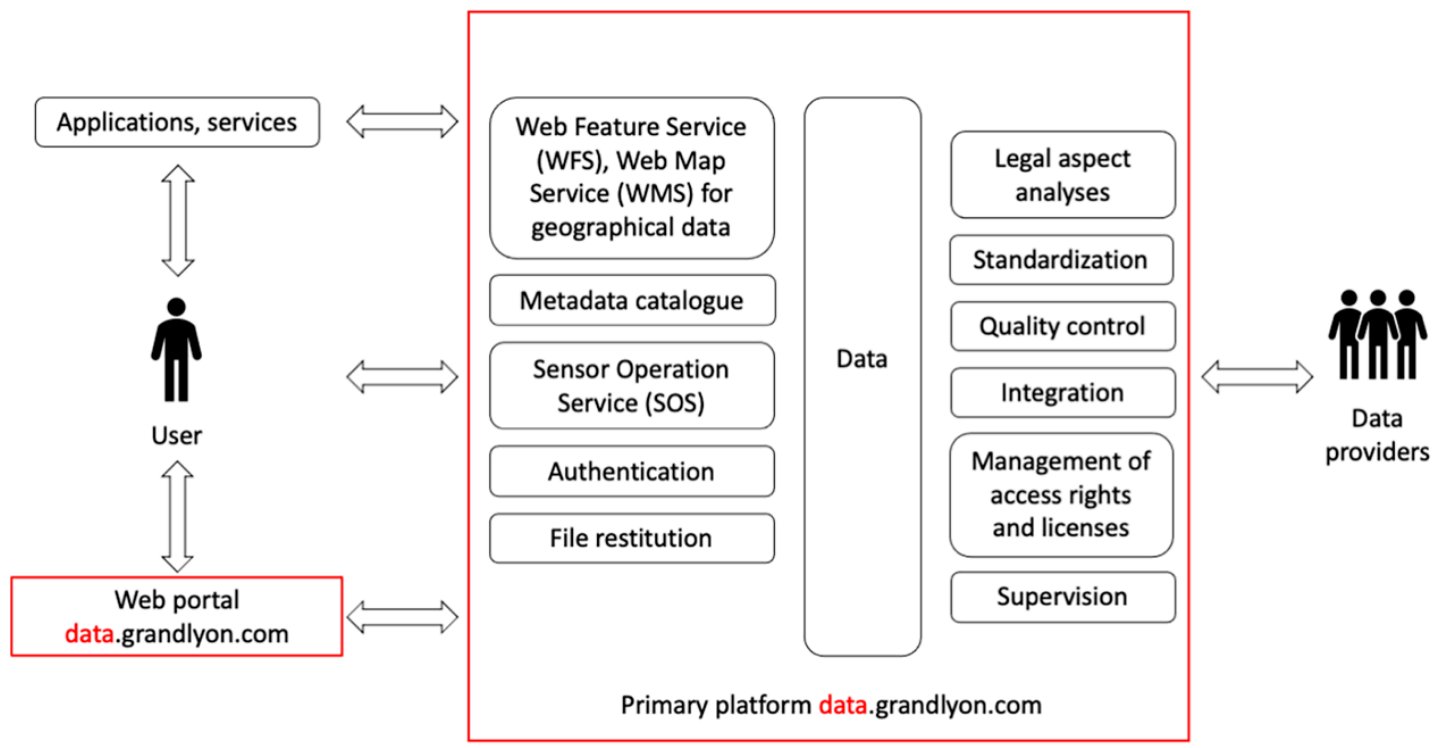

Figure 1. Overview of Grand Lyon's Smart Data Platform (SDP) that was expanded to include data from La Confluence within the Smarter Together (ST) project. 
In Lyon, as holistic building refurbishment and energy performance were paramount in the La Confluence refurbishment, SPL and Grand Lyon sought an overall "energy view". Therefore, data sent to the Grand Lyon data platform originates from smart power meters of the electricity utility, smart district heating heat meters, building energy management systems (BEMS), and photovoltaic production. Weather and mobility data are also a source for the urban data platform.

\subsection{Building upon the City Intelligence Platform in Munich}

In Munich, the City aims to save energy, reduce carbon dioxide emissions, and facilitate a cleaner, more efficient traffic flow. To achieve these goals, digital technologies are indispensable for real-time information, communication, data exchange, analysis, and connectivity. In this context, the Bavarian capital has explicitly committed itself to seek a healthy balance between smart technologies and workable solutions for people in their everyday lives. Smart data, not big data, is the motto. The solutions collect, analyze, and provide access only to data that delivers immediate benefits to residents and/or the whole city. Top priority is always given to current privacy and data protection legislation with the implementation of leading-edge data protection requirements.

The SDP is synchronized with the Data Gatekeeper (DGK) presenting a comprehensive blueprint about data handling including data privacy and data security aspects in a Smart City context [20].

The Data Gatekeeper (DGK) describes the main structures to design the data platform. The platform and the Gatekeeper were designed and implemented in parallel, taking into consideration the different iterations that were made during this phase. For that reason, the Data Gatekeeper also includes a comprehensive set of golden rules that could serve other cities to get a better understanding of the potential traps and hurdles potentially appearing when dealing with Smart-City data. The aim was to set the rules and learnings from the project to use them in other projects in the future. Figure 2 shows a schematic of the DGK.

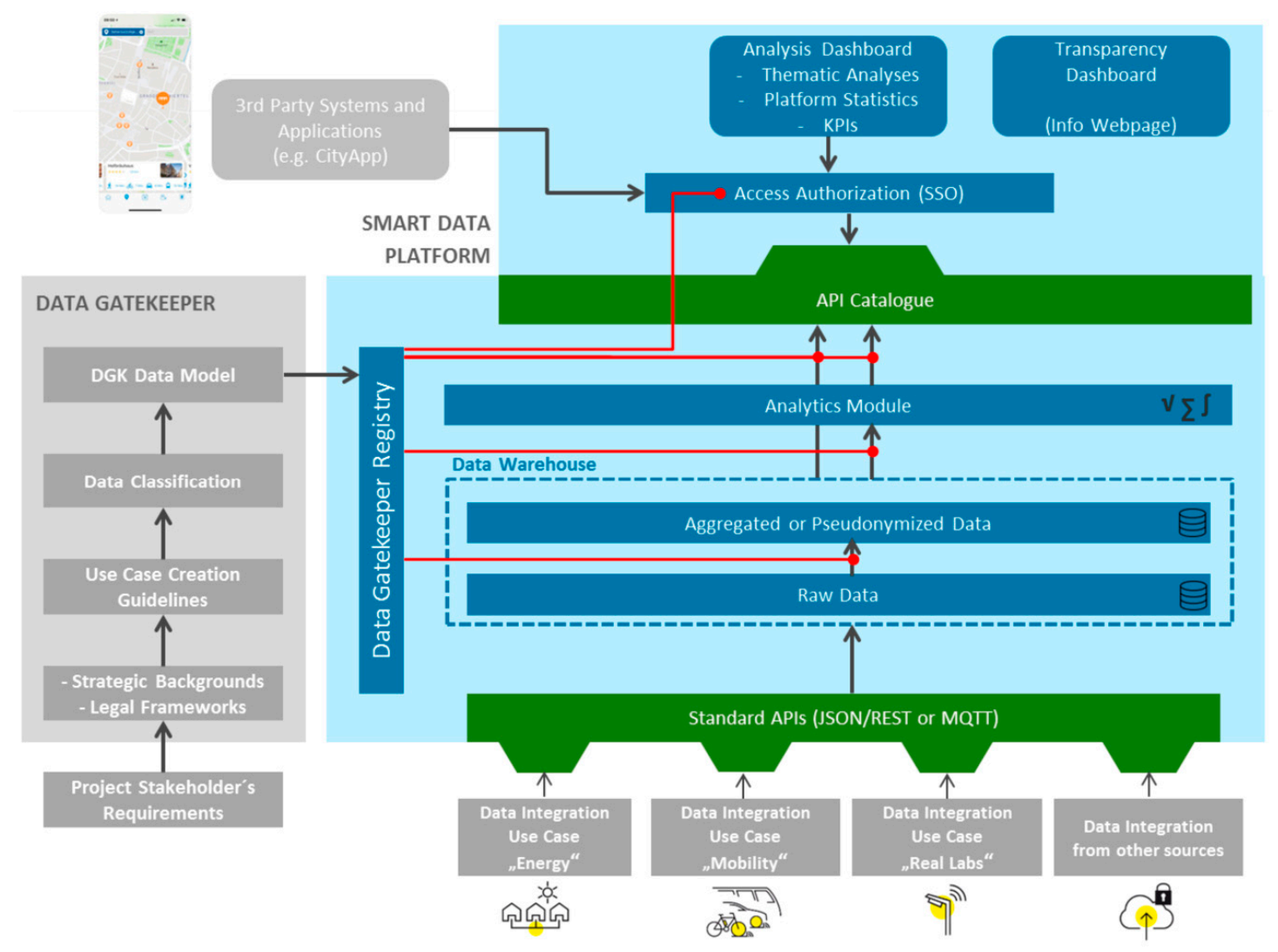

Figure 2. Overview of Munich's data gatekeeper registry to SDP [20]. 
The DGK is an internal tool for the ST Munich partners. A separate transparency dashboard for citizens is described in Section 3.6.

\subsection{Development of a New Data Platform for Vienna}

Vienna developed a completely new data platform for the ST demonstration projects in the Enkplatz and Geiselberg districts based upon future internet ware (FIWARE).

Vienna focuses on the energy, ICT, and mobility solutions in a smart neighborhood emphasizing citizen engagement and governance. The Vienna DMP collects, transfers, stores, exchanges, and visualizes data from various demonstration projects. Customized models are developed to derive key performance indicators (KPIs) to assist in the evaluation and interpretation of gathered data. Specific applications utilize the smart infrastructure to facilitate interaction with citizens through web and mobile applications. Figure 3 illustrates the schematic overview of the digital platform.

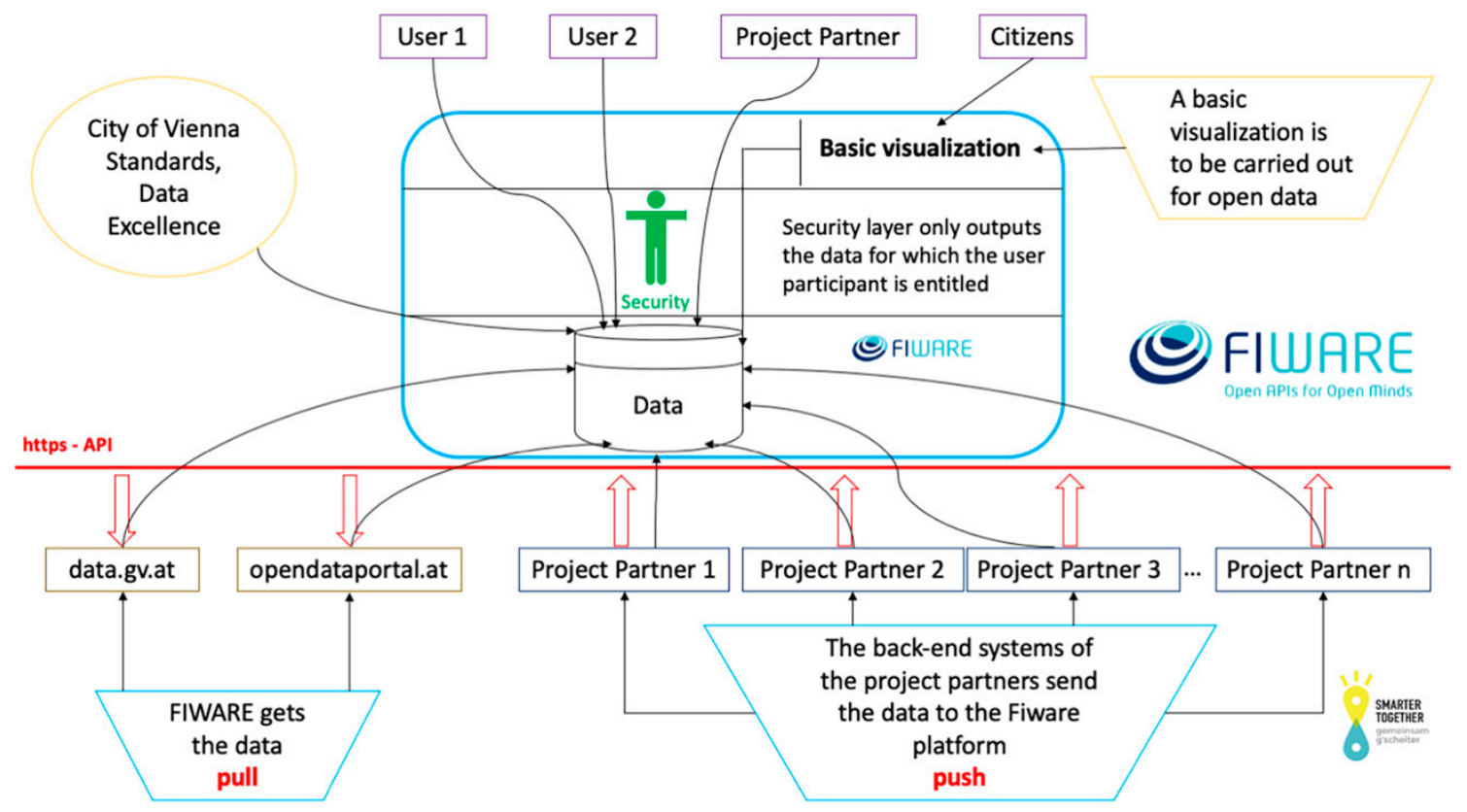

Figure 3. Overview of the Vienna Data Platform and central data management system [16].

Vienna developed the Smart City Wien (SCW) Platform based on the Supervisory Control and Data Acquisition (SCADA) system architecture operated by the Municipal Department for Construction and Building Management, MA34. The SCADA platform uses automated data processing and was developed with an open-source structure and was temporarily implemented using an external European cloud solution with the support from the FIWARE Foundation. However, FIWARE is only equivalent to a base-operating system consisting of several modules. The City of Vienna, therefore, needed to develop its application or user interface, either using all necessary FIWARE modules or adapting a ready-made solution. The VM9 FIWARE application was chosen due to time and cost restraints.

\section{Results}

The project case studies focused on adapting, modifying built and operational city infrastructure by enhancing or establishing computational intelligence to gather relevant data, and making this infrastructure controllable in the long-term using ICT-related technologies and mechanisms [19].

Each dedicated smart meter collection point supplies local data platforms. Other data sets document residential thermal comfort (Munich), electricity output from locally installed photovoltaic arrays (Lyon), the heat output from renewable energy sources (Lyon 
and Vienna), distances travelled by shared e-bikes and e-cars (all LHCs), and air quality (Munich). Municipal KPIs for all LHCs to reach climate neutrality are related to reducing total building energy consumption and transport-related $\mathrm{CO}_{2}$ emissions and pollutants while increasing heat and electricity outputs from renewable energies. The purpose of building energy monitoring through the data platform is to document and verify building energy consumption pre- and post-renovation. Digital infrastructure for traffic supports the reduction of fossil-fuel vehicle uses by coordinating key data about new cycling, and e-mobility infrastructure for both transport operators and local citizens as transport users.

The combined actions improve the quality of life for all inhabitants and their involvement in the district redevelopment process through cocreation of customized new citizen services.

The characteristics of the platforms in each city are illustrated in Table 1. All cities use open government data (OGD) as common inputs. However, the chosen technologies, security concepts, visualization tools, and data formats are unique to each city.

Table 1. A descriptive comparison of digital management platform (DMP) characteristics in each lighthouse city (LHC) [11].

\begin{tabular}{|c|c|c|c|}
\hline Criteria & Lyon & Munich & Vienna \\
\hline Data Provided & $\begin{array}{l}\text { OGD, energy consumption (electricity, } \\
\text { heating, etc.) and production } \\
\text { (photovoltaic systems) data, mobility } \\
\text { data }\end{array}$ & $\begin{array}{l}\text { OGD, geodata infrastructure, } \\
\text { mobility (car-sharing) data, } \\
\text { temperature and humidity } \\
\text { data, movement data, fine } \\
\text { dust and pollutant data }\end{array}$ & $\begin{array}{l}\text { OGD, energy consumption } \\
\text { data, mobility and public } \\
\text { transport data, air quality (air } \\
\text { pollution) data. }\end{array}$ \\
\hline Data Formats & $\begin{array}{c}\text { OGC WMS, WFS, WCS, rest, OSM } \\
\text { (WMS-T) }\end{array}$ & API Rest HTTPS \& JSON data & $\begin{array}{c}\text { Lightpad, PHP-FPM, } \\
\text { Memcached, MySQL, } \\
\text { MongoDB, Context Broker, } \\
\text { Apache Cassandra, CKAN } 2.6\end{array}$ \\
\hline Data Flow & APIs & Open data from sensors & Openstack API \\
\hline Technologies & $\begin{array}{c}\text { Geosource, Mapserver, Apache, } \\
\text { PostGIS-Open Source-ITL } \\
\text { Software from a third-party company }\end{array}$ & $\begin{array}{l}\text { City intelligence platform } \\
\text { (CIP) from Siemens, Postgre } \\
\text { SQL, NoSQL }\end{array}$ & FIWARE-Open Source \\
\hline Security Concept & $\begin{array}{l}\text { Access to different kinds of data is based } \\
\text { on licenses }\end{array}$ & $\begin{array}{c}\text { Data gatekeeper for access } \\
\text { control }\end{array}$ & FIWARE-Security layer \\
\hline Visualization Tools & Confluence Monitoring System & $\begin{array}{l}\text { Visualization-base map } \\
\text { integration possible, city map }\end{array}$ & $\begin{array}{l}\text { VM9-GUI, IoT interfaces, } \\
\text { FIWARE visualization }\end{array}$ \\
\hline $\begin{array}{l}\text { Existing Operating } \\
\text { Data Platform }\end{array}$ & $\begin{array}{l}\text { Yes, } 2016 \text { changeover from the Toshiba } \\
\text { platform to the Grand Lyon platform }\end{array}$ & Yes, until 31 July 2021 & No \\
\hline
\end{tabular}

The following sections outline the characteristics of each SDP according to the properties shown in Table 1.

\subsection{Data Provided}

The data gathered and stored within a city's urban platform vary from city to city. Four types of data are normally collected:

1. Power and heating generation, and distribution;

2. Building energy consumption;

3. E-mobility energy management and traffic;

4. Local climate and pollution data.

Energy and heat flow, pollution, local weather, traffic, and geographic location data are gathered and sent to the platforms to provide static, periodical, and real-time information. The data is collected from the monitoring infrastructure in the LHCs. Roles and responsibilities in the monitoring process are defined. Data-sharing agreements have been signed with providers with data flowing from the various collection sites. 
The ST project enabled collection of a wide range of data sets to establish new municipal services for the Lyon La Confluence district, the Lyon project district in ST, by building upon a district data platform created within the Franco-Japanese Lyon Smart Community Program from 2011 to 2016.

Most of the datasets in Lyon are open government data, accessible without restriction to citizens. The data sets are used by private companies, such as Transit, Citymapper, and architectural and engineering firms. Datasets are integrated into private companies' databases for further development of new citizen services.

No personal data is collected in Munich and Vienna in standard use cases, as the citizens who participated in cocreation workshops rejected the idea. Real-time building data is used to improve facility and energy management, error detection, and system calibration in Vienna.

Demonstration applications in the LHCs included data management from building energy refurbishment, car-sharing, e-mobility solutions (including e-bikes, e-buses, e-vans, and e-forklifts), neighborhood renewable energy supply, lamppost sensor data, district heating networks, and street lighting. Developing web and mobile applications for citizens was a focus for developing potential applications of the realized DMPs.

\subsection{Data Formats}

The three cities have installed different sensors with the solutions developed within ST, and therefore feed different data back to their platforms. All SDPs use open governmental (OGD), and data about building energy efficiency, mobility, and air pollution. However, aside from the OGD, the data types vary.

The projects carried out in each demonstration area dictate which data is retrieved. For example, the Grand Lyon IT Department integrates data collected via the smart meters to the digital platform, adapting to the distinct data formats.

Full platform workflow integrates numerous raw data sources from multiple data providers in Munich. The data output from data processing and analysis is visible in a dashboard. The interpreted data is an input for dedicated application programming interfaces (APIs) ready for reuse in mobile telephone applications or other digital contexts. Data providers designed a wide range of APIs for the smart data platform. A diverse array of technical interfaces and different data types can integrate into one system for cross-topic analyses and user cases. The central purpose was to apply and establish proven IT-Standards, both for the API and the data formats, to prevent future "vendor-lock in".

Public data is already available in Vienna. The collected data is aggregated per building and collected daily to respect the inhabitants' privacy. Individual data collection has a 30-min time-step. Aggregated energy consumption values are used.

\subsection{Data Flow}

Data management and smart services projects are divided into three main categories comprising infrastructure, platforms, and applications as presented in Figure 4.

Although data seems fluid and invisible, it is a constant challenge to organize data due to the dependence on various technical infrastructures and legal arrangements.

The data type obtained raises privacy issues as not all data can be collected, especially individualized data. There are also technical, economic, and energy limitations that restrict data flow to the platform.

In Lyon, the data platform is accessible to all internet users through a web portal. The main portal functionality is the search engine for finding data sets using keywords. The Grand Lyon data platform collects, edits and publishes more than 800 sets of data, mainly from the databases of the Metropolis' services in various fields: traffic infrastructure, waste management, geographical information, finance, education, and environmental data.

The guidelines for new buildings specify selected energy data sharing with the Grand Lyon data platform. Contractors install smart meters meeting the data-collection specifications. Smart meters and sensors connected to the city platform are integrated as a 
requirement for ST eco-refurbished buildings. The owners of the existing buildings in Lyon La Confluence must install smart meters as a part of their program of construction works.

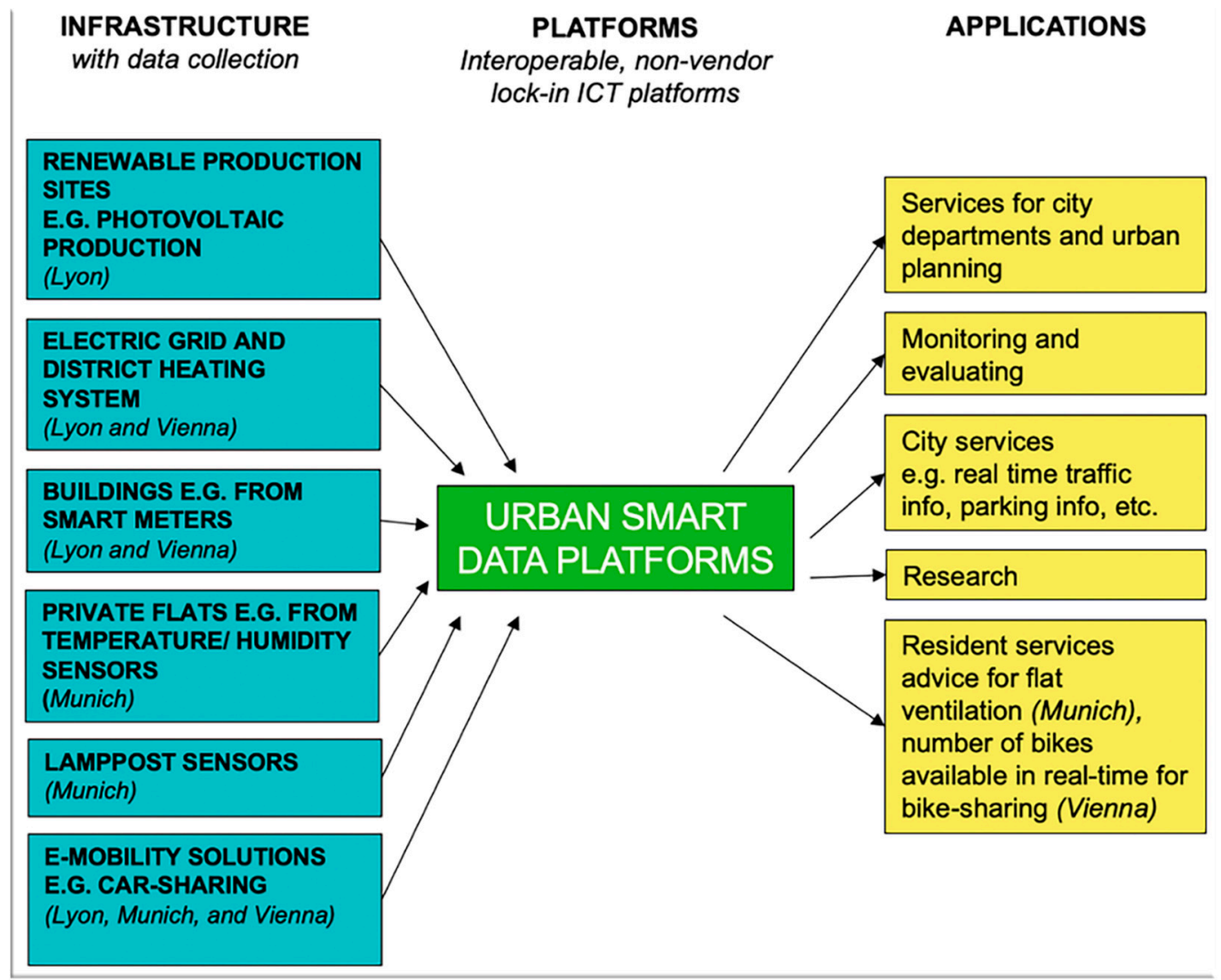

Figure 4. Data flow within the established data management platforms for the three LHCs. From left to right: Infrastructure components as inputs (turquoise), smart data platform repository and analysis (green), and applications as outputs (yellow).

Since the solutions monitored within ST are implemented for, and in cooperation with the LHCs, there is an agreement that all collected data are shared with the data management platforms of each city. In Vienna, the demonstrated building solutions focus on social housing that is mainly in municipality ownership.

The Munich DGK was implemented according to the protocol, which can be described as a process and workflow for cities handling Smart City-related data. The Data Gatekeeper (DGK) structures, rules, and data protection options were customized for the projectspecific use cases in Munich. Citizen engagement processes have been organized in Munich for all use cases in addition to the DGK process descriptions and recommendations.

The DGK concept defines a hierarchical workflow starting with the use case definitions (objectives), then looking at concerned institutions and ending with technologies to be implemented. The levels show the possible technologies and players to consider in the design phase of Information and Communication Technologies (ICTs) driven innovation, where data and data safety plays a vital role. Therefore, the Munich DGK is a mix of process and technology to serve as a basis for decision-making. The basic idea is to have a workflow description for operational staff and city decision-makers to follow when smart services, i.e., data platforms and/or infrastructure applications, will be implemented in Munich.

The overall functionality of the SDP has successfully shown following an end-to-end data exchange scenario within a proof-of-concept demonstrator using the Smart Home Sensors and including all main system elements: raw data input, data correlation, APIdefinition, and smart data output.

The urban data platforms in Lyon and Vienna are operational. In Munich, a digital twin and urban data platform are in the planning stage with a planned launch in 2021, 
as a follow-up project. The SDP will be an operational data platform based upon the experiences from ST. The project findings and the Data Gatekeeper Projects also help to develop and implement future services for the Munich Digital Twin.

Monitoring is underway in Vienna. Sensors in the gymnasium transmit data to Vienna's Municipal Department for Construction and Building Management via a Siemens system before being transferred to the data platform. The data exchange is now available for applications like data visualization for external stakeholders with anonymized results.

\subsection{Technologies}

In Lyon, the data platform is composed of three layers: back, middle, and front office. At the back-office level, the Géosource software collects and manages internal data sources, while cataloguing metadata. The feature manipulation engine extraction transfer loading (FME ETL) tool integrates and organizes external data sets, generates a copy of the data catalogue, and authenticates the API in the middle office. In the front office, data is replicated and catalogued. The API is authenticated; and data is published through the authenticated APIs, MapServer, and SOS formats. The middle and front-office are hosted outside the municipal IT infrastructure by an external internet service operator, ensuring ready availability and security. Furthermore, Grand Lyon developed the CMS web application to provide new energy data-based services on the smart data platform.

The Lyon CMS software is divided into two parts. The first part is comprised of the back-end for data storage and computation, and front-end for the graphic user interface (GUI). The second part is to use case-oriented specific data computation, data visualization, and data export.

A prototype web-based application was developed to test usability and APIs in Munich. After the prototype test runs, priorities determined the new features of the Muenchen.de mobile phone application. Munich uses existing modules for a fully integrated system. The Muenchen.de application is not an isolated solution. API interfaces to partners using a de facto standard REST (Representational State Transfer) API and JSON (JavaScript Object Notation Format) for transferring data. The Muenchen.de application for iOS and Android operating systems is running successfully since the initial rollout. The prototype web-based application was developed further creating the mobility station information pillars in the Neuaubing-Westkreuz district.

The Smart Data Platform in Munich was designed and implemented using the city intelligence platform (CIP) as a theoretical blueprint. The DGK developed by the city of Munich and Fraunhofer IAO Institute for Industrial Engineering (Fraunhofer-Institut für Arbeitswirtschaft und Organisation) is a blueprint that is focused on data handling, including data security and data privacy. It describes the necessary technical, legal, and structural prerequisites to handle Smart City data and Smart City data platforms in general. Just building a data platform without the understanding of the complexity behind the complete end-to-end processes was not the goal of the City of Munich.

A central aspect of ST is monitoring smart solutions. The Austrian Institute of Technology (AIT) developed a purpose-built integrated monitoring concept for the Viennese quarter. The City of Vienna adopted the "open by default" principle, opting for a FIWARE open-source data platform. The City of Vienna joined the FIWARE Foundation and is a member of OASC (Open and Agile Smart Cities) to promote open standards and their use [21].

The central component of Vienna's FIWARE Platform is the Orion Context Broker, which aggregates data and transfers any platform into a context-aware system-turning a spreadsheet of numbers into actionable insight.

Orion is open-source software designed to consider all specifications, thus saving developers' time and money. The Context Broker provides an open standard API to communicate with all other applications in the ecosystem, such as an open government database or a dashboarding application. The API also enables data to be sent to the historical database, the Data Lake, for monitoring developments across a timeline. Both the 
Context Broker and the API were developed by the FIWARE Association based on global NGSI (Next Generation Service Interfaces) specifications. FIWARE's version of the NGSI interface is a REST API that uses HTTP (Hypertext Transfer Protocol) to transfer context data between applications. The API allows data to be retrieved for both one-time queries and subscriptions.

Vienna chose relevant data models from FIWARE to define how entities and attributes relate to each other. This helps the Context Broker to understand how data can be aggregated from various sources, including open government data, other public sources of data, and other local data providers.

The latest NGSI V2 data model is used for the API with enhanced support for linked data. This data model eases the creation of associations between entities, facilitating the establishment of a meaningful data context. A security layer ensures that each stakeholder only sees their authorized data [22].

\subsection{Security Concept and Legal Contexts}

Digital services for various stakeholders must consider three major issues: privacy policies, legal contexts, and data quality to meet stakeholder requirements while ensuring data security for accessing the same SDP.

The Grand Lyon data platform is registered with the French Data protection authority. No personal data is stored. Instead, an alternative "self-data" solution, complementary but separate from the data platform, has been developed to deal with data privacy. More than ten data sharing agreements were signed between residential data providers supplying data to the Grand Lyon data platform. The data-sharing agreement between Enedis and Grand Lyon complies with the French national data privacy regulation [17].

The IT Department of the Greater Lyon Region oversees data security. Data centers in France, operated by subcontractors and overseen by the Grand Lyon IT Department, store and manage the data.

Tenants in new buildings with smart meters, officially sign data-sharing agreements with Grand Lyon, with building owner and manager approval. SPL, the La Confluence urban developer, coordinates the data-sharing agreements with the tenant associations on behalf of Grand Lyon. Each building owner must sign a data-sharing agreement for sharing their building data as a precondition for receiving an ST subsidy for ecorefurbishment.

Explicit consent must be obtained from the owners and tenants for individual household data use. Currently, data collection includes monitoring and assessment of environmental and energy performance. It does not require individual household data in the Lyon La Confluence urban district. Data access is limited to the project partners involved in monitoring. All partners signed exclusive data-sharing agreements.

The Munich DGK supports decision-makers and operational stakeholder by giving recommendations in various phases of project development regarding data usage and privacy requirements [20]. One exception was the collection of temperature and humidity data within privately owned flats. In this case, permission from each affected condominium owner was sought to handle condominium addresses.

When sensitive data is required for a use case, collection and data use must be discussed and approved by the city-data security manager following an existing set of municipal data regulations and guidelines complying with EU-GDPR (General Data Protection Regulations). An agreement can then be drafted for personal data use sign-off by each individual. The operator of the Munich SDP ensures that different levels of data security are in place. Data operation security is a standard for IT operators. During the project, the Munich SDP was not an integral part of the existing municipal IT infrastructure but remained in a Siemens/VMZ lab infrastructure (VMZ Berlin $\mathrm{mbH}$ ) with the same protection levels as the municipality to maintain project flexibility [20].

Every data set used in the City of Vienna is classified according to the municipal Data Excellence Strategy. The principle of "Open by Default" applies, but certain data can, of course, not publicly disclosed [23]. 
Data collection does not focus on individual households or entities respecting individual data privacy. Thus, identification of single persons or households is not possible. Even still, the monitoring concept was not fully accepted by all relevant stakeholders, mostly due to perceived legal data protection and privacy issues from collecting personal data. Personal data use was discussed at length until satisfactory detail about personal data handling was satisfied. The City of Vienna ICT Department includes standard municipal data safety and security mechanisms and is incorporated into the city's overall ICT strategy [16].

\subsection{Visualization Tools}

Data dashboards need to be developed to visualize results and provide services to the citizens and the municipality. The lighthouse cities have chosen to develop applications building on already existing digital infrastructures reflecting local goals and regulations. Figure 5 illustrates examples of visualizations from each city.
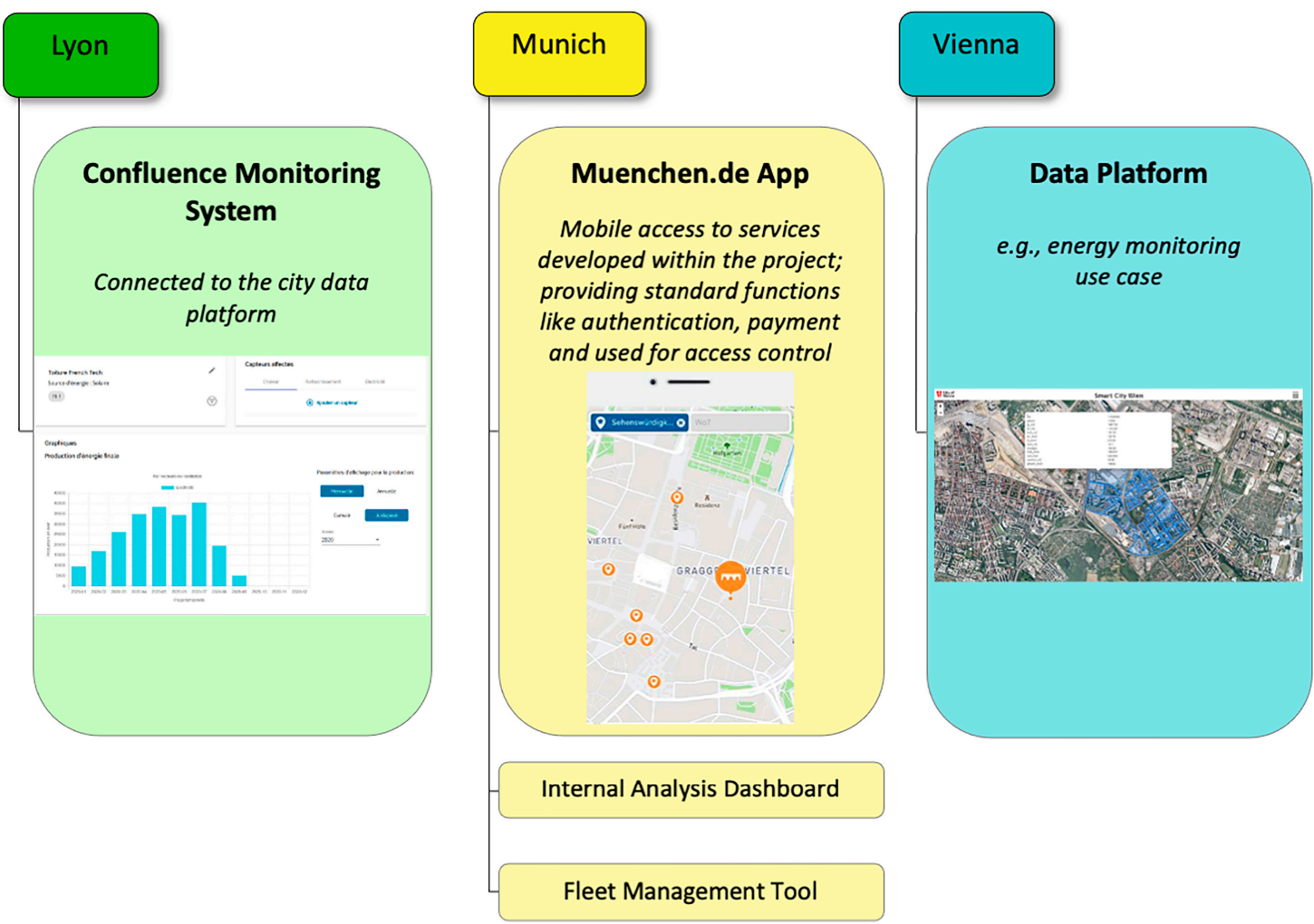

Figure 5. Visualizations of collected data on each city data platform in Lyon (left) [24], Munich (center) [25], and Vienna (right) [26].

The data platform in Lyon creates a collaborative hub for local utilities such as GRDF, Enedis, and others. Energy consumption distribution in the territory is now visible because of data exchange and sharing. La Confluence can expand capabilities to analyze energy data as the project enabled content management system development. The CMS integrates La Confluence district. Internal negotiations are underway in Grand Lyon to extend the system throughout the City of Lyon.

Munich has a three-part DMP: The Analysis Dashboard, Muenchen.de-App, and the Transparency Dashboard.

All energy, mobility, and smart lighting sensor data was transferred to the internal Smart Data Platform. The Analysis Dashboard is a part of the internal Smart Data Platform and visualizes the raw data graphically. The Analysis Dashboard has password-protected access only for internal ST Munich team members. 
An API from the Smart Data Platform transferred selected sensor data to the server feeding the publicly accessible Muenchen.de-App. Data could be visualized as part of an integrated digital city map on smartphones with either iOS or Android operating systems. A user can click on icons of "intelligent lampposts" to view selected ST-sensor data. The visible data on the digital map was simplified for data comprehensibility and clarity. Figure 5 shows a screenshot from the mobile app.

The City of Munich created a separate "Transparency Dashboard" (TD) for project transparency about monitoring activities to all citizens during the initial project phase. The TD is an open standalone webpage where information about the collected data, analytics goals, and data retrieval options are displayed [20]. It does not show any analytics or raw data.

The TD was cocreated as a response to the citizen stakeholders in Munich who requested transparency about the monitoring process and application of sensor data. It was agreed that the Analysis Dashboard was too complex for the public. The result was the TD with detailed explanations about the equipment and sensors used, collected data, reasons for data collection, which data analyses were carried out, and where the data would eventually be published (or not). The approach gained trust from those involved in the public discussions. Although the TD is not a direct data link, feedback given reflected understanding and acceptance of the efforts to make the whole data collection process and analysis within ST-Munich transparent and open [20].

The FIWARE application used in Vienna offers an appealing user interface, as desirable user management already integrates numerous modules. The FIWARE platform is equipped with an interface based on the VM9 application and offers basic visualization to view data in its raw form. During the test run, the data platform operated as a cloud solution using Netzlink's Open Stack installation. The platform relocated to the City of Vienna servers after the test run.

\subsection{Existing and New Operating Data Platforms}

Information bundling in a platform offers opportunities to generate new knowledge, to provide quality assurance, and to increase the efficiency of the administrative process. Cities should not have to buy data from third parties but be able to use self-generated information efficiently [16]. Therefore, within the project, either new data platforms were created, or existing data platforms were adapted to map the individual projects in each LHC.

The Lyon La Confluence Region entered the world of "intelligent" development through the major demonstration projects in a previous framework: Ilot Hikari, an allpurpose positive energy block; an electric car-sharing fleet; renovation and monitoring of two eco-renovated buildings; and development of a municipal monitoring system.

SPL created a municipal data platform assisted by the Japanese company, Toshiba during the Franco-Japanese Lyon Smart Community Program. Lessons learned from the first-generation SDP was applied to develop the new Grand Lyon data platform and CMS. The CMS is connected to the Grand-Lyon Data Platform, which establishes the API to send data to the CMS.

Within the framework of this project, SPL Lyon Confluence provided the link between all stakeholders. Since the data platform is managed by Grand Lyon, decisions relating to adapting the SDP to changes to the La Confluence quarter must be agreed by SPL and Grand Lyon.

The Munich Smart Data Platform (SDP) is an adaptation of the Siemens-owned $\mathrm{CIP}$ that was developed to meet ST project requirements. The new platform design and implementation meet all use case requirements for data integration, processing, analysis, and exchange in the Neuaubing-Westkreuz district. The SDP synchronizes with the Data Gatekeeper (DGK) presenting a comprehensive blueprint on data handling within a Smart City context including data privacy and data security aspects. 
Unlike Lyon and Munich, Vienna did not yet have its urban data platform at the city-level, at the beginning of the project. Vienna began by analyzing different local and international digital urban solutions in detail, and by evaluating different urban applications in Amsterdam, Lyon, Munich, Barcelona, London, Milan, and Bern. Based on the analysis results, Vienna selected a FIWARE-based (future internet ware-based) opensource solution, which has been also used for implementing the City of Vienna IoT Strategy. FIWARE fulfilled the main selection criteria: independence from a specific supplier and the possibility to further develop existing modules and solutions [16].

FIWARE retrieves the data from two open data portals: data.gv.at and opendataportal.at. Other data providers send their data to the FIWARE platform via HTTPS and predefined APIs.

\subsection{Digital Mobility Services for Citizens and Stakeholders}

In ST Lyon the NAVLY autonomous shuttle operated from 2016 until September 2019. The distances travelled, and hourly electricity consumption data were collected during this period and communicated to the data management platform enabling vehicle performance and malfunctions to be remotely diagnosed. Navya manufactured the shuttle bus, and KEOLIS, Lyon's public transport network operator managed the fleet. Bluely was a municipal e-car sharing program that operated in the Greater Lyon Region from October 2013 to September 2020. The private e-car fleet was operated by Bolloré on behalf of Grand Lyon. Bolloré operated both the electric car fleet and the charging points. The charging points in La Confluence were expanded as part of the ST project. The distances travelled by the e-cars, and the charging point use frequency in La Confluence was transmitted to the Grand Lyon data platform to analyze the acceptance and use of e-cars by the Lyonnaise population. Figure 6 shows the different e-mobility solutions in each LHC.

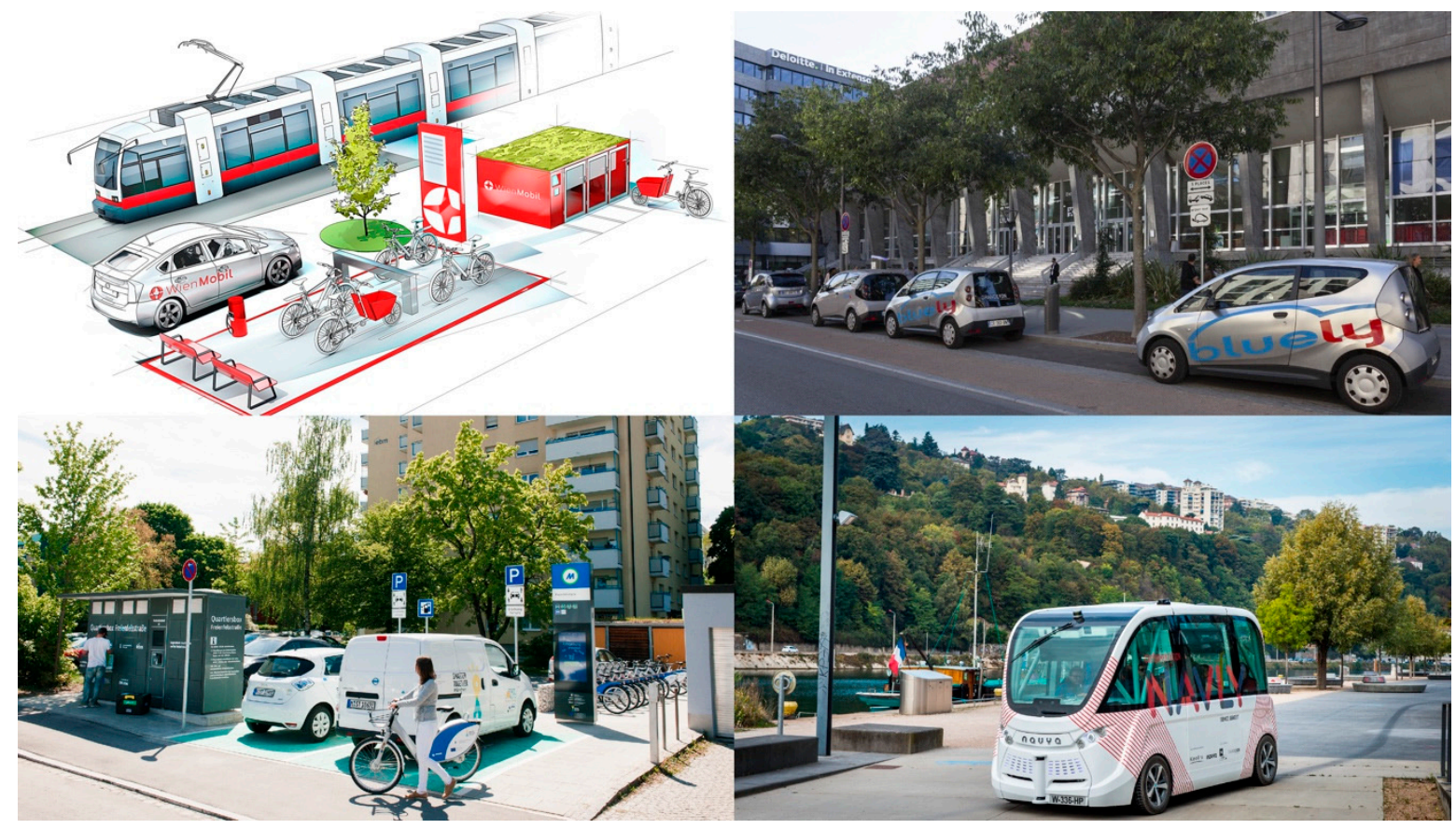

Figure 6. Clockwise from top-left, WienMobil Station at Simmeringer Platz, Wiener Linien [27]; NAVLY autonomous shuttle bus in Lyon, Laurence Danière (top-right), Bluely fleet at Bluely Station, Aurélie Pétrel (bottom-right); and Westkreuz Munich Mobility station, Dominik Parzinger.

Power consumption of the Compagnie Nationale du Rhône (CNR) charging points has been monitored to determine the number of car trips by privately owned electric vehicles in Confluence, and the Perrache-Sainte-Blandine neighborhood. CNR deployed a network of charging points from Genève to Avignon in the South East of France. Including Lyon, 
there is a total of 27 charging stations with 54 charging points [28]. Grand Lyon only has access to data from the Lyon CNR charging points in La Confluence.

Open-access mobility data is available on the Grand Lyon online dashboard from Grand Lyon's partners. JCDecaux is in charge of the "Vélo'v" bike-sharing fleet and stations that provide real-time information about the availability of bikes and e-bikes for each station across Lyon [29].

One of the central use cases for the Smart Data platform in Munich was data integration and analysis from eight newly installed mobility stations in the project area as seen in Figure 6. The mobility stations offered data from four different sources: car sharing usage, rental bikes, rental e-pedelecs, and rental e-trikes. The data platform analyzed and visualized the car-sharing distances driven per sharing car and station, and the number of rented bikes, the rental station, and the delivery station. Based on this data, a local ranking of usage and business impact of the newly installed stations was carried out, clearly showing useful results for the mobility station planning team.

At the beginning of the project, only electric cars from Munich STATTAUTO, a professional car-sharing provider, and rental-bikes from MVG (Münchener Verkehrsbetriebe), the public mobility services from the City of Munich, were able to contribute to the project goals. No private cars were included.

The public transit operator of the City of Vienna, Wiener Linien, built a mobility station in the Simmering project district [30]. The project includes two private mobility sharing providers: Caruso (e-car-sharing) and Sycube (e-bike-sharing). Three Caruso e-cars with dedicated charging stations have been available to residents since the project start-up [31]. Sycube provided "Sim Bikes" for the project district. Renting an e-bike allows cyclists to explore the limits of the Simmering project area and also to tour the Viennese Central Cemetery, the location of one of the e-bike collection points [32]. An overview of the mobility concept is in Figure 6.

An E-Carsharing concept and implementation was part of a cocreation process with a target group of tenants from the Hauffgasse housing cooperative. The target group was not only involved in the design phase but is also active in the management of the local Caruso fleet for the social housing complex [11,30].

Vienna promoted industrial e-mobility in the Siemens [33] and Post AG [34] companies. Electric cars, bikes, forklifts, and vans were provided with charging points integrating all transport modes.

\section{Discussion: Key Challenges}

\subsection{Data Quality}

In Lyon, data collection requirements, including time-step and data types, was designed in cooperation with Enertech, a specialist in designing and monitoring building performance. The parameters were defined together with the main stakeholders to find a relevant solution for all. Applicable monitoring and building evaluation data were defined considering technical and economic feasibility of data collection, the required data collection equipment, and identifying possibilities to streamline cost and technical complexity. The identified monitoring infrastructure was integrated into different project tenders. The resulting data collection strategy reflects the troubleshooting process, thereby avoiding unanticipated problems after completion of construction or renovation works. Building monitoring is thus able to transition smoothly in the post-occupancy phase. This approach also avoided dedicating resources to collect irrelevant data.

In Munich, the required data quality and content in the project are first described in a use case. The stakeholders in the Munich project classified their delivered data before sending it. Depending on the classification level, the data will be threatened in the data platform. The classification level for all ST uses cases in Munich was developed and described in the Data Gatekeeper. For the SDP, this stepwise and parallel approach forces all involved stakeholders to deal with their data, taking into consideration to think about and define the "real value of the data". This creates work on various levels of 
complexity related to the different tasks at the same time but is a worthwhile exercise for all participants and management levels. In Munich, data sharing agreements have also been set up with different internal and external stakeholders. The agreements also included the data classification settings, described in the DGK.

Data management is a social and communicative challenge between many different players. In Vienna, the general challenge of data management has been solved through a common understanding and a clear idea of the use cases and outcomes. It is managed by clear responsibilities regarding data governance and data management. This includes all necessary measures for the timely provision of reliable data in the required quality, with the vision that the City of Vienna will become a "data excellent" data capital city.

\subsection{Application of the Data Results}

Each city's dedicated SDP has customized applications. The data platforms link related domains, such as energy production and consumption, for insights into the interdependencies while addressing additional policy, governance, and citizen requirements in implementing and utilizing the new services and apps. Each city did not develop the same applications.

Munich deployed a large network of smart lampposts with WLAN and local weather and pollution sensors. Vienna introduced LED street lighting with free WLAN hotspots. The newly developed "intelligent lampposts" in Munich gather climate and traffic data, provide lighting, and a public WLAN connection. Each lamppost has a dedicated power supply for the climate and pollution sensors separate from the lighting power supply. Climate and pollution sensors measure local climate conditions. Other sensors track traffic and manage parking. A designated fiberglass internet cable connects several lampposts for the public M-WLAN hotspots (Munich WLAN) for free internet connectivity for all. Sixty intelligent lampposts provide lighting, free public Wi-Fi, and collect local climate and air pollution data.

No digital system to measure air quality has been officially used in the City of Munich. The project provided a chance to test air quality sensors in a real lab scenario. Based upon the experiences and the encouraging results, discussions have recently begun about officially using next-generation digital air quality measuring equipment instead of an analogue infrastructure.

The Smart Data Platform in Munich included several use cases like energy, mobility, and smart lampposts. The resulting knowledge building in all participating departments of the Munich City Administration was outstanding. Based on the experiences and discussions during the whole project, a new view on digitalization in the urban environment resulted in the City. The value of city data and their future impact was discussed intensively. The Data Gatekeeper Report, Deliverable D 4.4.1, discussed all aspects of Smart Data, data privacy, data analytics, and their possible future impact on a city like Munich [20]. One very fruitful aspect was the open learning environment during the entire project duration; it was allowed to make mistakes and learn from them. The learning environment helped to build knowledge and reject unusable results.

Lyon and Vienna implemented a series of deep thermal building renovations with smart energy meters indicating building energy consumption before and after building renovations and quantifying the calculated effectiveness of deep thermal renovations in detail for the cities and their research partners.

Deep-thermal renovations in Munich maintained legacy meters and the city administration is strategizing how the heating and electricity meters will be incorporated into the overall energy monitoring plan.

Since 2018, several new bike rental providers established urban mobility services in Munich but were not able to be integrated into the ST project. In the future, consideration of all mobility stakeholders in mobility-analysis platforms is to be included for a comprehensive overview of the real potential of various urban mobility scenarios. 
Due to complexity and time-critical reasons, API-integrations into the Munich MVG and STATTAUTO databases were not feasible when the SDP commenced. It was decided to provide the mobility station's raw-data quarterly and manually via e-mail and Excel tables. Manual integration of a continuous data flow into an SDP is simple. However, the process is extremely time-consuming and contains high error potential. Therefore, continuing manual entry is not recommended for future use even though the basic elements of the different use cases could be standardized and reused. Automating data entry for standardized analysis is a goal to be developed at a future stage. Exchanging knowledge and experiences between Munich and Lyon improved dashboard development.

Munich's backend services require further development. However, the user interface for viewing analysis results in the Analysis Dashboard is a crucial component of the SDP. The interface delivers added value to the ST SDP. The screen interface underwent several development iterations to design a robust interface. Defining filter options and selecting suitable user interfaces are necessary to analyze big data sets meaningfully.

\subsection{Benefit Models}

In ST, a benefit model describes the effects of data platforms and smart services [18].

Most datasets in Lyon are openly accessible to citizens. The data sets are also used by private companies, such as Transit, Citymapper, and architectural and engineering firms. Datasets are integrated into private companies' databases for development of new citizen services.

Data is used by Grand Lyon to develop its own digital services. For example, Grand Lyon provides the Onlymoov multimodal route planner based on data from the data.grandlyon.com platform: roads, road traffic information, information on public transport, and on the self-service bicycle system [35-37]. The Onlymoov calculator offers metropolitan residents the best mobility solutions at any given time. Public and private initiatives can benefit from the data platform to deploy digital services as shown in Figure 7.

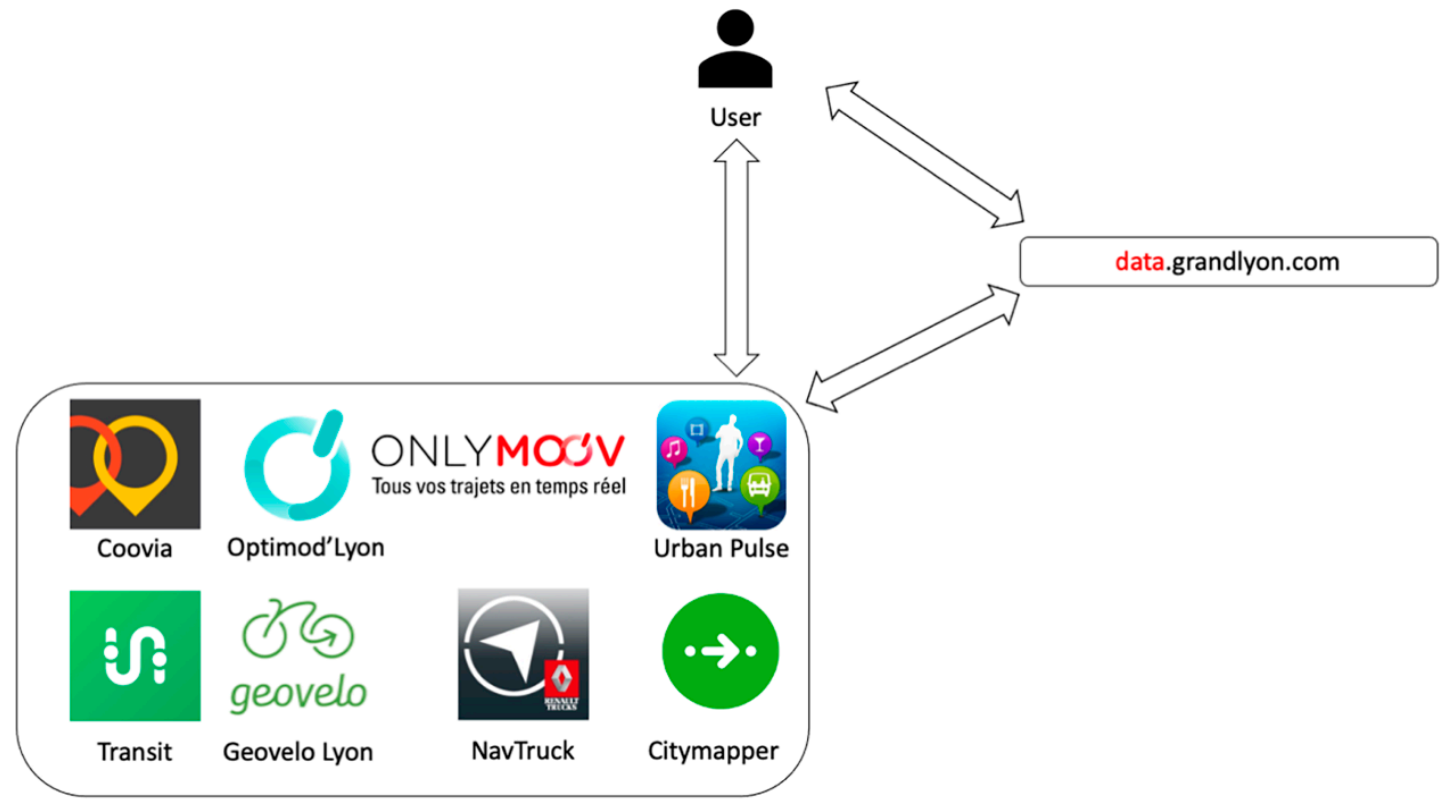

Figure 7. Examples of internal and external applications that have access to the data platform in Lyon [14].

All energy data sets feed the CMS for three energy use case scenarios:

1. Checking new buildings conformity to the energy performance specifications set by SPL,

2. Evaluating the energy performance of building renovations and building operations, 
3. Tracking energy consumption and production by the Lyon-La Confluence District according to the zero-carbon objectives in the WWF Sustainable Action Plan, and

4. Tracking the level of use of electric vehicle systems.

Originally, the Munich Smart Data Dashboard was only to be used during the project. Munich decided to expand the data infrastructure beyond the project incorporating the knowledge gained during the project to design and launch a next generation Digital Twin with an Urban Data Platform.

The Munich DGK is one of the projects envisaged as a standardization activity. The $\mathrm{SDP}$, based on the DGK concept, is one of the replication projects.

The City of Vienna and the ST project team developed possible use cases across several departments. E-mobility sharing applications were implemented including sensor data from mobility operators. Energy consumption data from a new gymnasium, static data from renovated buildings, and numerous previously available OGD supplied the data platform.

Several use cases were realized on the Viennese SCW comprising energy, building, and mobility data. Three other use cases were developed for car and bike sharing, and E-Logistics. The first use case was the energy consumption monitoring of the existing Enkplatz school gymnasium prior to renovation. The energy monitoring system was extended to the City of Vienna's social housing building stock where two buildings were refurbished and monitored within the project. The final step is implementing the City of Vienna IoT strategy within the FIWARE-based SCW platform.

Vienna's strategy follows the "Open by Default" guiding principle of their Data Excellence Strategy [38]. Open data brings innovation, transparency, and participation by citizens, research institutions, start-ups, and many business institutions, such as through applications used by other innovation projects or by data journalists. Sharing open data enables fact-based participation, objective discussion, and generates added value for all stakeholders in the data economy. Open data enables the creation of new applications to assist citizens by offering better service delivery.

Data platforms are becoming an integral part of cities [39-41]. They enable municipalities to handle Smart City data and form the basis for new digital services for citizens and local governance. The data platform architecture should be standards-based but is also strongly dependent on the specific requirements and conditions of each locality, especially the existing IT-infrastructure. A data platform will not replace the numerous existing municipal data entities, but rather will combine existing digital infrastructure elements to a logical common analytics and visualization tool. The data platform is a system of systems that is usable by every government department, external stakeholders, and citizens with different permissions and access.

The three LHCs implemented their data management platforms by either expanding existing data platforms or creating a new platform supporting monitoring processes in the ST-implemented demonstration projects. The "urban data platforms" represent a fundamental element of the integrated processes handling data collection, processing, monitoring, and visualization from each implemented project. The consolidated data contains several domains of building and energy infrastructure components and smart solutions related to building management systems, energy consumption and energy efficiency measures, on-site renewable energy generation, traffic, and mobility management systems.

The compiled and processed data build the foundation for the envisioned KPI-based monitoring of the sustainable impacts of the realized measures in social, economic, and environmental dimensions. Following this effort, the three LHCs developed their urban data management platform and smart services in coordination with the local city stakeholders and by making use of P2P knowledge exchange with other cities. The outcomes are summarized in the following paragraphs illustrating the fulfillment of the overall project goals and each city's objectives. 


\subsubsection{Lyon: Open-Source CMS}

New data-based services are to be developed with municipalities and public organizations. Enedis, the electricity utility, harmonizes electric smart meter development in Lyon La Confluence with the national rollout plan. Enedis has been involved since the project proposal stage to oversee electricity consumption monitoring.

Within the framework of the Grand Lyon digital data platform, the partnership with the La Confluence translates into an experimental project of energy data recovery. This is the first time in Lyon that the platform has recovered energy data. The platform adapted a new format and programmed new modules to harvest the new data typology allowing for future multi-level replication. The first level collects data for an energy assessment enabling the main building energy consumers to be identified.

Appropriate measures increasing energy performance are selected. France has a large real estate portfolio including multiple public building typologies, including schools, universities, and government buildings. The collection and analysis of energy data on a district level will be scaled up to improve building energy performance on a municipal scale.

Smarter Together enabled the development of the CMS integrating energy data only from the La Confluence district. The CMS uses data sent to the Grand-Lyon data platform from more than ten building complexes enabling a global understanding of the energy flows by collecting and displaying the energy data of the area to improve the urban planning process. The same data will be applied to improve the planning, design, and operation of public infrastructures for the greater Lyon Metropolis. Additionally, the CMS will be supplied with electric smart meter data from Enedis, the electricity grid operator. Negotiations are underway to extend the CMS throughout Lyon.

Cooperation between Grand Lyon and the La Confluence allows for innovations to accelerate, developing digital services to measure air quality, health and well-being, and mobility. The smart digital platform data and digital technology continually improves the quality of the urban project.

\subsubsection{Munich: Developing a Digital Twin}

The SDP provides a flexible tool to integrate data from various use cases that are stored and refined in the database layer based on the adopted standardized API. The data is processed and visualized for the platform's dashboards and provided to thirdparty application services. The most important use cases of the SDP are the ST intelligent lampposts with local climate sensors. In addition, the Smart Home sensors measure temperature and humidity in selected Munich dwellings.

The development of the Data Gatekeeper, design and implementation of the Smart Data Platform, and collaboration between all internal and external stakeholders created end-to-end processes benefitting the City of Munich immensely. Two important developments resulted:

1. An operational Munich-based digital twin, representing the city digitally including a 3D-representation, sensors, and other information enabling municipal departments to implement various use cases including simulation, visualization, and analytics based on the experiences and knowledge gained during the project.

2. Knowledge networks based on project experiences that clearly show advantages and future opportunities of digitalization and Smart City projects in the German and European city networks, data community and start-ups networks, and municipal interdepartmental networks.

Munich decided to define, test, and implement a digital twin based on excellent SDP experiences, overall ST project results, knowledge building, internal and external community feedback, and increasing demand for IT-managed Smart City solutions in Munich. The Munich digital twin has a much broader and more complex architectural structure and will be able to implement more complex use cases than the SDP has been designed for. From an IT perspective however, the digital twin is a direct and main follow-up project of the ST SDP. 


\subsubsection{Vienna: Expansion towards a Digital Twin}

Vienna's smart data platform will continue to be used by the City of Vienna serving future Smart City projects. It will be expanded to become Vienna's digital twin. The data platform relocated from the temporary cloud infrastructure to the City of Vienna's permanent data center. The user interface is under revision and for integration with the Austrian security portal. FIWARE is an IoT middleware and data source that can be applied to cooperate with other Austrian cities. The intent is to expand the SCW Platform for use in other Austrian cities such as Graz and Linz, building a nationwide open-source FIWAREbased platform. The more cities that choose an open-source solution, the more synergies can result from the accumulated experience.

Efficient and cost-effective integration of the building stock in local energy communities remains a challenge for municipalities in general. Experiences from the LHCs have shown that the effectiveness of financial subsidies to building and condominium owners for connection to local renewable energy generation can significantly increase when coupled with a professional consultant in the framework of an early stage funded activity, e.g., on behalf of the city, acting as an owner's representative for the entire refurbishment process. Without the dedicated owners' representative, many homeowners do not take advantage of federal and municipal subsides, due to poor understanding of the application process, and the difficulty of reaching unanimity between condominium owners for building refurbishment measures.

Agreement is not only needed between the building and individual condominium owners, municipal bodies, and the utilities, but also the tenants. An integrated approach with representation from all stakeholders for the entire process is needed to implement district-level energy communities [42].

Consensus from all stakeholders is also required for sharing building, energy consumption (and production, in case small-scale prosumers' assets, such as PV panels) and mobility monitoring data in DMPs. The collective decisions influence the future architecture and products for both local government and citizens [43].

Building use patterns have changed during the pandemic. Daily residential occupancy periods have increased due to teleworking, home schooling, and temporary and/or sudden unemployment caused by the pandemic. Those remaining in offices have lower occupancy rates due to social distancing regulations, while also having higher ventilation requirements to maintain good air hygiene for minimizing the spread of the virus. The higher recommended mechanical and window ventilation rates conflict with energy efficiency and thermal comfort goals [44]. It is possible to have false readings from the energy profiles if a household is affected by energy poverty and can no longer afford to heat/cool their homes adequately. Indoor air hygiene, and possible future isolation requirements should be considered when planning new energy communities together with flexible building uses [44].

Future expansion of the DMP can use the data from building uses and energy patterns to develop with effective indoor air hygiene strategies, while meeting wellbeing and energy efficiency targets [45].

Data from mobility uses can help cities meet citizens' requirements in real-time reflecting the shifts in alternative mobility uses and for connecting pedestrian-scale quarters towards designing the 15-min city.

\section{Conclusions}

All three lighthouse cities benefitted from their experiences developing digital infrastructure for citizen and municipal services during the project. The future planning procedures in the LHCs are still not finalized due to the massive impact of the pandemic on nearly every municipal activity. Nevertheless, it can be said that the pandemic clearly showed the necessity to base future decisions about almost every urban aspect on precise and overarching digital city data. The pandemic challenge emphasizes the need for con- 
tinuous improvement and implementation of digital Smart City platforms like a digital twin [43].

By including local climate conditions within the digital infrastructure, the relationship of natural conditions to pollution, indoor environmental quality, outdoor comfort, and human activities can be better understood in relation to renewable energy production, and related economic impacts for prosumers [45].

It is becoming apparent that the urban issues directly and indirectly caused by climate change require support from digital infrastructures to analyze local conditions, and potentially provide an integrated framework for an iterative process supporting climateadaptive design solutions [46]. The digital dashboard can be expanded through digital urban acupuncture (DUA) to show urban pressure points [47] where people congregate, and to assess whether the identified places have adequate grey, blue, and green infrastructural elements and systems to foster a healthy city. The concept was first introduced by Iaconesi and Persico [48] and can certainly fit the current state of play as described in the lighthouse cities analyzed in this paper.

Through the SDPs, the potential arises to transform urban planning from a static top-down approach, to a responsive ongoing cocreation dialogue involving citizen participation with local planners like in the lighthouse cities of Smarter Together. Implemented SDPs are exhibiting huge potential to support a myriad of use cases and dashboards to assist interdisciplinary municipal "climate teams" to reach climate neutrality goals [49]. With this digital infrastructure, new use cases responding to the real-time evolving needs of the population can consider microclimate conditions, the relationship of natural conditions to pollution, indoor environmental quality, outdoor comfort, urban economic and transportation activities, risk of energy poverty, integration of the circular economy, and increased direct citizen input. In terms of climate adaptation strategies, balancing areas of hard surfaces with green-blue infrastructure [50] in cities can be effective to combat the urban heat island effect, sudden and intense heavy rain [51], and capturing particulate matter in the air [52] for urban evolution towards healthy cities for all.

To cite just one of the topics that have come to the forefront during this COVID-19 pandemic, as human vulnerability to respiratory diseases increased globally, it is worth mentioning that municipalities are currently discussing how to advance towards NOxneutrality [53] and leverage COVID-19 as an opportunity for healthy economic recovery, stronger community building, and more explicit considerations of urban democracy [54]. The digital response to the current public-health crisis (which is characterized by very high "information-intensity" especially due to the massive use of social media) has triggered a sort of digital revolution by boosting teleworking, creating a web-based community to exchange information on how to manage this unprecedented situation, revolutionized work habits and life-work balances, promoted virtually delivered services, and even 3D printing of essentials [55].

The specific role of ICT in fighting against the spread of the pandemic has proven to be very important, but also equally very challenging, with evident phenomena of increasing the digital divide $[45,56]$. Traditional blue-collar workers, i.e., factory workers, skilled agricultural, fishery, and forestry workers, and elementary occupations often do not have the option to work from home [57,58]. Casual work, where higher percentages of unskilled workers are engaged, is also susceptible to economic downturns [59]. These workers often face the difficult decision of choosing between working and risking exposure to the virus or staying at home unemployed [59].

Already vulnerable groups are at higher risk in the long-term to losing access to digital and overall literacy because of loss of employment and education opportunities, combined with isolation due to extended lockdown measures [56]. Therefore, greater effort must be taken by municipalities to integrate their needs so that they will not be left behind.

Moreover, access to education, which in this exceptional circumstance is also being delivered also remotely, has proven to be more than ever highly jeopardized by the economic 
and social conditions of students' families, due to the uneven access to ICT (even to a simple internet connection), which is even more exacerbated in developing countries [60,61].

Contact tracing mobile apps have been devised to alert people who have been in close contact with someone who tested positive to the virus, but their alleged endangerment of citizens' privacy has also been criticized [62], not to mention the very limited diffusion at the urban scale. Moreover, improper use of ICT is also one of the main reasons for the so-called "infodemics", i.e., the exposure of the population to a deluge of information, unfortunately often biased by fake-news, which makes it difficult for people to recognize reliable and trustworthy guidance when needed [63].

What we need is therefore an "appropriate" use of digital tools [64], by which urban ecosystems have proven to be able to respond and adapt to unexpected and disruptive changes, implementing evidence-based design on the basis of the interactions of citizens with and within the urban and natural environment, while progressing towards regenerative, sustainable, and inclusive cities.

Author Contributions: Conceptualization by É.V., N.M.-S., R.A. and B.M.; methodology, software, validation, and investigation-A.H., U.M., E.G. and F.X.P.; data curation-A.H., B.G., U.M., E.G., B.L., G.H. and F.X.P.; writing—original draft preparation, R.A., B.M. and N.M.-S.; writing-review and editing, N.M.-S., B.M., É.V., U.M., E.G., F.X.P., A.H., A.M. and M.B.A.; visualization-C.W., B.M. and N.M.-S.; supervision-É.V. and N.M.-S.; project administration-É.V.; funding acquisition, B.G., É.V., N.M.-S., A.M., and M.B.A. All authors have read and agreed to the published version of the manuscript.

Funding: Smarter Together has received research funding from the European Union's Horizon 2020 Research and Innovation Programme under grant agreement No. 691876 as part of the Horizon 2020 Smart Cities and Communities initiative.

Data Availability Statement: Individual data is not publicly available following GDPR regulations. Analyzed mobility data for Lyon is available at https:// data.grandlyon.com. Data from the Vienna use cases are available at https://smartdata.wien.

Acknowledgments: This article is based upon work from COST Action (www.cost.eu) RESTORE CA16114, supported by COST (European Cooperation in Science and Technology). COST (European Cooperation in Science and Technology) is a funding agency for research and innovation networks. Our Actions help connect research initiatives across Europe and enable scientists to grow their ideas by sharing them with their peers. This boosts their research, career and innovation. We thank Martin Kaltenhauser-Barth, Florian Mandel, and Andrea Costa from the Münchner Gesellschaft für Stadterneuerung for providing input to the sections relating to Smarter Together Munich. We thank all Smarter Together collaborators, past and present, for their efforts.

Conflicts of Interest: The authors declare no conflict of interest. The funders had no role in the design of the study; in the collection, analyses, or interpretation of data; in the writing of the manuscript, or in the decision to publish the results.

Abbreviations
$\begin{array}{ll}\text { API } & \text { Application Programming Interfaces } \\ \text { BEMS } & \text { Building Energy Management Systems } \\ \text { CIP } & \text { City Intelligence Platform (Munich) } \\ \text { CMS } & \text { Confluence Monitoring system (Lyon) } \\ \text { CNR } & \text { Compagnie Nationale du Rhône } \\ \text { DGK } & \text { Data Gatekeeper } \\ \text { DMP } & \text { Digital Management Platform } \\ \text { FIWARE } & \text { Future Internet Ware } \\ \text { FME ETL } & \text { Feature Manipulation Engine Extraction Transfer Loading } \\ \text { GDPR } & \text { General Data Protection Regulations } \\ \text { GUI } & \text { Graphic User Interface } \\ \text { ICT } & \text { Information and Communication Technologies } \\ \text { JSON } & \text { JavaScript Object Notation Format } \\ \text { LHC } & \text { Lighthouse City }\end{array}$




$\begin{array}{ll}\text { MVG } & \text { Münchener Verkehrsbetriebe } \\ \text { NGSI } & \text { Next Generation Service Interfaces } \\ \text { OASC } & \text { Open and Agile Smart Cities } \\ \text { OGC } & \text { Open Geospatial Consortium } \\ \text { OGD } & \text { Open Government Data } \\ \text { REST API } & \text { Representational State Transfer Application Programming Interface } \\ \text { SCADA } & \text { Supervisory Control and Data Acquisition } \\ \text { SCW } & \text { Smart City Wien (Vienna) } \\ \text { SDP } & \text { Smart Data Platform } \\ \text { SPL } & \text { SPL Lyon Confluence } \\ \text { ST } & \text { Smarter Together } \\ \text { TD } & \text { Transparency Dashboard }\end{array}$

\section{References}

1. Courmont, A.; Le Galès, P. Gouverner la Ville Numérique; PUF: Paris, France, 2019.

2. Hey, T.; Tansley, S.; Tolle, K. The Fourth Paradigm: Data-Intensive Scientific Discovery; Microsoft Research: Redmond, WA, USA, 2009.

3. Beckouche, P. La révolution numérique est-elle un tournant anthropologique? Débat 2017, 193, 153-166. [CrossRef]

4. Courmont, A. Où est passée la smart city? Firmes de l'économie numérique et gouvernement urbain; Cities Are Back in Town Working Papers; Sciences Po Urban School: Paris, France, 2018; pp. 1-27.

5. Guéranger, D.; Mathieu-Fritz, A. Smart city at work, Intermédiation sociotechnique et «souveraineté de la donnée» dans une administration locale. Réseaux 2019, 218, 41-75.

6. Anthopoulos, L. Smart City Emergence: Cases from Around the World, 1st ed.; Elsevier: Amsterdam, The Netherlands, 2019.

7. Galderisi, A. Chapter 1-The smart city metaphor to foster collaborative and adaptive decision-making processes in the face of climate issues. In Smart, Resilient and Transition Cities; Galderisi, A., Colucci, A., Eds.; Elsevier: Amsterdam, The Netherlands, 2018; pp. 3-10.

8. Daniélou, J. Smart City: Origine et Concepts; PUCA France: La Défense, France, 2019; pp. 1-68. Available online: http://www. urbanisme-puca.gouv.fr/IMG/pdf/smart_city_origine_et_concepts.pdf (accessed on 15 January 2021).

9. Winkowska, J.; Szpilko, D.; Pejić, S. Smart city concept in the light of the literature review. Eng. Manag. Prod. Serv. 2019, 11, 70-86. [CrossRef]

10. Chapuis, J.-Y. Villes et territoires: La grande transformation. Popul. Avenir 2020, 746, 14-16. [CrossRef]

11. Smarter Together. Deliverable D 10.1.2: Comparative Analysis of Co-Created Smart City Solutions; SPL Lyon Confluence: Lyon, France, 2019; pp. 1-140.

12. Barns, S. Smart cities and urban data platforms: Designing interfaces for smart governance. City Cult. Soc. 2018, 12, 5-12. [CrossRef]

13. Barrett, M.A.; Humblet, O.; Hiatt, R.A.; Adler, N.A. Big data and disease prevention: From quantified self to quantified communities. Big Data 2013, 1, 168-175. [CrossRef] [PubMed]

14. Balogun, A.-L.; Marks, D.; Sharma, R.; Shekhar, K.; Balmes, C.; Maheng, D.; Arshad, A.; Salehi, P. Assessing the potentials of digitalization as a tool for climate change adaptation and sustainable development in urban centres. Sustain. Cities Soc. 2020, 53, 101888. [CrossRef]

15. European Commission. Smart and Inclusive Solutions for a Better Life in Urban Districts. CORDIS EU Research Results. 2021. Available online: https:/ / cordis.europa.eu/project/id/ 691876 (accessed on 5 January 2021).

16. Smarter Together. Deliverable 5.4.2: Central Data Management System Vienna; SPL Lyon Confluence: Lyon, France, $2019 ;$ pp. 1-43. Available online: https:/ / smarter-together.eu/file-download/download/public/1019 (accessed on 10 October 2020).

17. Smarter Together. Deliverable D 3.4.1: Lyon Confluence Community Management System (CMS); SPL Lyon Confluence: Lyon, France, 2019; pp. 1-46.

18. Smarter Together. Deliverable 2.5.3: Report on Current Implementation Status for Data Management Platform E Smart Services Solutions; City of Vienna: Vienna, Austria, 2019; pp. 1-159.

19. Smarter Together. Deliverable D 2.1.3: Report on Peer-to-Peer Knowledge Exchange Network and Workshop; SPL Lyon Confluence: Lyon, France, 2019; pp. 1-60. Available online: https://smarter-together.eu/file-download/download/public/1617 (accessed on 12 December 2020).

20. Smarter Together. Deliverable D 4.4.1: Smart Data Platform Munich; City of Munich: Munich, Germany, 2019; pp. 1-190. Available online: https: / / smarter-together.eu/file-download/download/public/1257 (accessed on 5 January 2021).

21. City of Vienna. Urban Data Platform. 2018. Available online: https://digitales.wien.gv.at/site/projekt/plattform-smartdatawien/ (accessed on 4 February 2021).

22. CEF Digital-Connecting Europe. The Number One Smart City in the World Uses CEF Context Broker to Effectively Manage Big Data. 2020. Available online: https://ec.europa.eu/cefdigital/wiki/display/CEFDIGITAL/2020/02/06/The+number+ one+smart+city+in+the+world $\% 2 \mathrm{C}+$ Vienna $\% 2 \mathrm{C}+$ uses $+\mathrm{CEF}+$ Context+Broker+to+effectively+manage+Big+Data (accessed on 22 September 2020). 
23. Lutz, B. Data Excellence: IKT Teilstrategie; Magistratsdirektion der Stadt Wien, Geschäftsbereich Organisation und Sicherheit Prozessmanagement und IKT-Strategie: Vienna, Austria, 2019; pp. 1-42.

24. Grand Lyon. Lyon Confluence Monitoring System; Grand Lyon: Lyon, France, 2020.

25. Portal München Betriebs-GmbH \& Co. KG. Perfect on the Go: The Munich SmartCity App. 2020. Available online: https: //www.muenchen.de/int/en/meta/iphone-android-app.html (accessed on 28 September 2020).

26. City of Vienna. Smart City Wien Use Cases: Smarter Together; City of Vienna: Vienna, Austria, 2020. Available online: https: //stp.wien.gv.at/smartdata.wien/gis/ (accessed on 15 December 2020).

27. Wiener Linien. Mobility Point in Simmering; Wiener Linien: Vienna, Austria, 2018. Available online: https://www.smartertogether. at/mobility-point-in-simmering/ (accessed on 3 January 2021).

28. CNR (Siège Social). Au Plus Près des Territoires. 2020. Available online: https://cnr.tm.fr/innovation-2/au-plus-pres-desterritoires/ (accessed on 29 January 2021).

29. Métropole de Lyon and JCDecaux. Historique des disponibilités des stations Vélo'v de la Métropole de Lyon; Online Mobility Dashbaord; Métropole de Lyon: Lyon, France, 2021. Available online: https:/ / data.grandlyon.com/jeux-de-donnees/historiquedisponibilites-stations-velo-v-metropole-lyon/donnees (accessed on 14 February 2021).

30. Smarter Together. Deliverable D 5.11: Simmering-Smart for the Future, Implementation Report of Smarter Together Vienna; City of Vienna: Vienna, Austria, 2019; pp. 1-44. Available online: https://www.smartertogether.at/wp-content/uploads/2019/06/ glossysummary_AT_EN_web.pdf (accessed on 7 January 2021).

31. Smarter Together. Start E-Carsharing in der Hauffgasse. Smarter Together: Smart and Inclusive Solutions for a Better Life in Urban Districts; City of Vienna: Vienna, Austria, 2017. Available online: https://www.smartertogether.at/start-e-carsharing-in-der-hauffgasse/ (accessed on 4 February 2021).

32. City of Vienna. E-Bikes am Zentralfriedhof. Smarter Together. 2018. Available online: https://www.smartertogether.at/e-bikesam-zentralfriedhof/ (accessed on 4 February 2021).

33. Smarter Together. Das Programmteam von Smarter Together zu Besuch: Zu Gast im Siemens-Werk Simmering; City of Vienna: Vienna, Austria, 2018. Available online: https: / /www.smartertogether.at/zu-gast-bei-siemens-simmering/ (accessed on 4 February 2021).

34. Smarter Together. Austrian Post Gets the "Energy Globe Award"; City of Vienna: Vienna, Austria, 2018. Available online: https:/ / www.smartertogether.at/oesterreichische-post-erhaelt-den-energy-globe-award/ (accessed on 3 February 2021).

35. Métropole de Lyon. Caméras Web Criter de la Métropole de Lyon; Online Traffic Dashboard; Métropole de Lyon: Lyon, France, 2021. Available online: https:/ / data.grandlyon.com/jeux-de-donnees/cameras-web-criter-metropole-lyon/donnees (accessed on 11 February 2021).

36. Métropole de Lyon. Tronçon Web Criter de la Métropole de Lyon; Online Traffic Dashboard; Métropole de Lyon: Lyon, France, 2021. Available online: https:/ / data.grandlyon.com/jeux-de-donnees/troncon-web-criter-metropole-lyon/donnees (accessed on 11 February 2021).

37. Métropole de Lyon. Comptage Criter de la Métropole de Lyon; Online Traffic Dashboard; Métropole de Lyon: Lyon, France, 2021. Available online: https:/ / data.grandlyon.com/jeux-de-donnees/comptage-criter-metropole-lyon/donnees (accessed on 11 February 2021).

38. City of Vienna. Data Excellence Strategy of the City of Vienna. 2020. Available online: https://digitales.wien.gv.at/site/en/dataexcellence-strategy-of-the-city-of-vienna/ (accessed on 3 February 2021).

39. Cosgrave, E.; Doody, L.; Walt, N. Delivering the Smart City: Governing Cities in the Digital Age; Arup, Liveable Cities, UCL, Smart City Expo: London, UK, 2014. Available online: https://www.arup.com/perspectives/publications/research/section/ delivering-the-smart-city (accessed on 5 February 2021).

40. EU Smart Cities Information System. Urban Data Platform. 2021. Available online: https://smartcities-infosystem.eu/ict/urbandata-platform (accessed on 5 February 2021).

41. Smart Cities Marketplace. Cities Are Becoming Digital-Urban Data Platforms Enable It. 2020. Available online: https: / / smart-cities-marketplace.ec.europa.eu/news/ cities-are-becoming-digital-urban-data-platforms-enable-it (accessed on 5 February 2021).

42. Economidou, M. Energy Efficiency Upgrades in Multi-Owner Residential Buildings—Review of Governance and Legal Issues in 7 EU Member States; Publications Office of the European Union: Luxembourg, 2018.

43. Dembski, F.; Wössner, U.; Letzgus, M.; Ruddat, M.; Yamu, C. Urban digital twins for smart cities and citizens: The case study of Herrenberg, Germany. Sustainability 2020, 12, 2307. [CrossRef]

44. REHVA. REHVA COVID-19 Guidance Document: How to Operate HVAC and Other Building Service Systems to Prevent the Spread of the Coronavirus (SARS-CoV-2) Disease (COVID-19) in Workplaces; REHVA: Brussels, Belgium, 2020; pp. 1-42. Available online: https: / / www.rehva.eu/fileadmin/user_upload/REHVA_COVID-19_guidance_document_V4_09122020.pdf (accessed on 12 December 2020).

45. Kloppenburg, S.; Boekelo, M. Digital platforms and the future of energy provisioning: Promises and perils for the next phase of the energy transition. Energy Res. Soc. Sci. 2019, 49, 68-73. [CrossRef]

46. Fertner, C.; Christensen, A.A.; Andersen, P.S.; Olafsson, A.S.; Præstholm, S.; Caspersen, O.H.; Grunfelder, J. Emerging digital plan data-New research perspectives on planning practice and evaluation. Geogr. Tidsskr. Dan. J. Geogr. 2019, 119, 6-16. [CrossRef]

47. Naboni, E.; Havinga, L. (Eds.) Regenerative Design in Digital Practice: A Handbook for the Built Environment; EURAC: Bolzano, Italy, 2019. Available online: https:/ / www.academia.edu/41213561/REGENERATIVE_Emanuele_Naboni_Lisanne_Havinga_ 
DESIGN_IN_DIGITAL_PRACTICE_A_Handbook_for_the_Built_Environment_REGENERATIVE_DESIGN_IN_DIGITAL_ PRACTICE_NOTES_ON_EDITORS_FOREWORD_INTRODUCTION_SUMMARY_ACKNOWLEDGEMENTS (accessed on 4 February 2021).

48. Iaconesi, S.; Persico, O. (Eds.) Digital Urban Acupuncture, in Digital Urban Acupuncture: Human Ecosystems and the Life of Cities in the Age of Communication, Information and Knowledge; Springer International Publishing: Cham, Switzerland, 2017 ; pp. $123-147$.

49. European Commission. Climate Adaptation in Cities. 2013. Available online: https://ec.europa.eu/info/eu-regional-andurban-development/topics/cities-and-urban-development/priority-themes-eu-cities/climate-adaptation-cities_en (accessed on 4 February 2021).

50. Bioveins. What Is Green and Blue Infrastructure? BIOVEINS Focuses on the Role of Green and Blue Urban Infrastructure on Biodiversity. What Is It? 2020. Available online: http:/ / bioveins.eu/blog/article2 (accessed on 31 January 2021).

51. Kunz, M. Sudden and Intense: Heavy Rain; Dunkelmann, M., Ed.; Helmholtz Climate Initiative: Leipzig, Germany, 2020.

52. Depietri, Y.; McPhearson, T. Integrating the grey, green, and blue in cities: Nature-based solutions for climate change adaptation and risk reduction. In Nature-Based Solutions to Climate Change Adaptation in Urban Areas: Linkages between Science, Policy and Practice; Kabisch, N., Korn, H., Stadler, J., Eds.; Springer International Publishing: Cham, Switzerland, 2017; pp. $91-109$.

53. Mizutori, M.; Sharif, M. OPINION: COVID-19 Demonstrates Urgent Need for Cities to Prepare for Pandemics. 2020. Available online: https:/ / news.trust.org/item/20200615120207-y321f (accessed on 4 February 2021).

54. Andreucci, M.B.; Marvuglia, A. Investigating, Implementing and Funding Regenerative Urban Design in a Post-COVID-19 Pandemic Built Environment: A Reading through Selected UN Sustainable Development Goals and the European Green Deal. In Rethinking Sustainability Towards a Regenerative Economy; Andreucci, M.B., Marvuglia, A., Baltov, M., Hansen, P., Eds.; Springer Nature: Cham, Switzerland, 2021.

55. Acuto, M. COVID-19: Lessons for an urban (izing) world. One Earth 2020, 2, 317-319. [CrossRef]

56. Hughes, C. Some implications of COVID-19 for remote learning and the future of schooling. In Current and Critical Issues in Curriculum, Learning and Assessment; UNESCO International Bureau of Education: Geneva, Switzerland, 2020; pp. 1-17.

57. Dockery, M.; Bawa, S. Working from Home in the COVID-19 Lockdown; Bankwest Curtin Economics Centre: Bentley, WA, USA, 2020. Available online: https:/ / bcec.edu.au/assets/2020/05/BCEC-COVID19-Brief-4_Working-from-home.pdf (accessed on 25 January 2021).

58. Galasso, V. COVID: Not a great equalizer. CESifo Econ. Stud. 2020, 66, 376-393. [CrossRef]

59. Eurofound. New forms of employment: 2020 update. In New Forms of Employment Series; Publications Office of the European Union: Luxembourg, 2020; pp. 1-72.

60. Büchi, M. Digital Inequalities: Differentiated Internet Use and Social Implications. Ph.D. Thesis, University of Zurich, Zurich, Switzerland, 2017; pp. 1-109. [CrossRef]

61. Di Pietro, G.; Biagi, F.; Dinis Mota da Costa, P.; Karpinski, Z.; Mazza, J. The Likely Impact of COVID-19 on Education: Reflections Based on the Existing Literature and International Datasets; Publications Office of the European Union: Luxembourg, 2020; pp. 1-50.

62. Rowe, F. Contact tracing apps and values dilemmas: A privacy paradox in a neo-liberal world. Int. J. Inf. Manag. 2020, 55, 102178. [CrossRef] [PubMed]

63. Pan, S.L.; Zhang, S. From fighting COVID-19 pandemic to tackling sustainable development goals: An opportunity for responsible information systems research. Int. J. Inf. Manag. 2020, 55, 102196. [CrossRef]

64. Schumacher, E.F. Small is Beautiful: A Study of Economics as If People Mattered; Blond and Briggs: London, UK, 1973. 